\title{
REVIEW
}

\section{Carbon monoxide poisoning in the 21st century}

Angela $L$ Chiew ${ }^{1,2,3}$ and Nicholas A Buckley ${ }^{1,2,3^{*}}$

\begin{abstract}
The world has experienced some very large shifts in the epidemiology of carbon monoxide poisoning, but it remains one of the most important toxicological global causes of morbidity and mortality. The diagnosis can be quickly confirmed with blood gases (pulse oximeters lack both sensitivity and specificity). Several strong predictors for serious neurological sequelae (prolonged loss of consciousness and elevated S100B) and reduced life expectancy (elevated troponin) are now reasonably well established. Despite this clearly defined high-risk group and extensive research into the pathophysiology, there has been little translation into better treatment. Much of the pathophysiological research has focused on hyperbaric oxygen. Yet it is apparent that clinical trials show little evidence for benefit from hyperbaric oxygen, and the most recent even raises the possibility of harm for repeated courses. More logical and promising potential antidotes have been under-researched, although recently both animal and small human studies suggest that erythropoietin may reduce S100B and prevent neurological sequelae. Major breakthroughs are likely to require further research on this and other treatments that may inhibit post-hypoxic inflammatory responses and apoptosis.
\end{abstract}

\section{Review}

Carbon monoxide (CO) results from the incomplete combustion of carbon-containing substances and is a colorless, odorless, and tasteless gas [1]. Exposure is most commonly from car exhaust (unleaded petrol cars produce about one tenth the amount of $\mathrm{CO}$ of older cars), faulty heaters, fires, and industrial accidents.

\footnotetext{
* Correspondence: nicholas.buckley@sydney.edu.au

${ }^{1}$ Clinical and Experimental Toxicology Unit, Department of Emergency Medicine, Prince of Wales Hospital, Barker Street, Randwick, NSW 2031, Australia

${ }^{2}$ Pharmacology, Sydney Medical School, University of Sydney, Sydney, NSW 2006, Australia

Full list of author information is available at the end of the article
}

It is clear that the epidemiology is driven by the source of $\mathrm{CO}$ and the diagnostic definitions applied. Notably, in the US, there appears to be quite a different pattern, with extremely large numbers of patients diagnosed but a relatively low death rate; for example, it was estimated that there were 1,000 to 2,000 accidental deaths due to $\mathrm{CO}$ exposure each year, resulting from an estimated 50,000 annual exposures [2]. The US case fatality of less than $5 \%$ for a poisoning that is highly lethal in most other countries may reflect several factors. Firstly, poisoning is largely from domestic heating (compare with fire or suicide) and is diagnosed (and treatment given) sometimes in the absence of any significant elevation of carboxyhemoglobin (COHb). For example, poison center calls in the National Poison Data System (2000 to 2009) found that $45.1 \%$ of the 68,316 unintentional, non-firerelated, $\mathrm{CO}$ exposures were managed at the site of exposure (that is, without any confirmation) [3]. Even of those attending a hospital and referred for hyperbaric oxygen ( $\mathrm{HBO}), 10 \%$ had an initial $\mathrm{COHb}$ within the normal range for heavy smokers $(<10 \%)$ and less than $1 \%$ had a recorded $\mathrm{COHb}$ over $50 \%$ [4].

This experience contrasts with most other countries where fires and suicidal poisoning (car exhaust or charcoal) are the leading causes of diagnosed $\mathrm{CO}$ poisoning. In Australia, for example, accidental poisoning accounts for less than $10 \%$ of calls about CO poisoning and the deaths often outnumber admissions [5]. It is therefore much easier to compare countries and examine trends over time by examining trends in $\mathrm{CO}$ poisoning deaths. Several Asian countries are facing rapidly evolving epidemics of $\mathrm{CO}$ poisoning from suicide by charcoal burning [6]. This increase occurred in the late 1990s, after a much publicized case in the media of a 38-year-old Hong Kong woman who committed suicide in a sealed bedroom by burning barbecue charcoal. The media depicted this means of suicide as painless and nonviolent. Subsequently, in Hong Kong and Taiwan, there has been an increasing incidence of charcoal burning suicides, which has led to an overall increase in the suicide rate of approximately $20 \%[6,7]$. A strategy to reduce the risk of misuse of charcoal burners is urgently 
required. Previous experience with the removal of coal gas and catalytic convertors has demonstrated that means restriction can be extremely effective in reducing $\mathrm{CO}$ suicides [8-10]. A range of possible solutions may need to be tried given the practical difficulties of restricting suicidal use of widely available domestic cooking equipment. On a more positive note, many countries have seen a substantial reduction in lethal car exhaust poisoning with the rise of catalytic converters $[8,11]$.

\section{Mechanisms of toxicity}

The most clearly established mechanisms for $\mathrm{CO}$ toxicity relate to tissue hypoxia. $\mathrm{CO}$ binds to hemoglobin with an affinity 200 to 240 times that of oxygen [12]. As $\mathrm{COHb}$ cannot carry oxygen, this leads to reduced oxygen-carrying capacity. Furthermore, $\mathrm{COHb}$ increases the affinity of the remaining sites for oxygen, meaning that oxygen release by the remaining oxygenated hemoglobin is also impaired. Thus, CO leads to impaired oxygen delivery to tissues and eventually to marked tissue hypoxia when compensatory mechanisms to maintain oxygen delivery fail.

However, tissue hypoxia is not the only possible explanation for the toxic effects seen. CO causes harm by both oxidative stress that follows a period of hypoxia and cellular damage by inflammatory processes. $\mathrm{CO}$ binds to and inhibits mitochondrial cytochrome oxidase, thereby directly inhibiting aerobic metabolism (analogous to the effect of cyanide). In the brain, $\mathrm{CO}$ binds to cytochrome c oxidase, which results in impairment of ATP synthesis and increased production of reactive oxygen species $[13,14]$. Inflammatory changes in acute CO poisoning include intravascular neutrophil activation due to interactions with platelets. This leads to neutrophil degranulation and perivascular oxidative stress [15]. While in rat models, $\mathrm{CO}$ exposure has been shown to precipitate abnormalities in myelin basic protein due to reactions with lipid peroxidation products [16]. Furthermore, some damage may be caused by the marked oxidative stress, free radical production, inflammation, and apoptosis seen when oxygenation improves and $\mathrm{CO}$ concentrations fall after severe poisoning (analogous to reperfusion injury) [15].

Unfortunately, much of the evidence on these effects has not used positive controls (that is, hypoxic injury not due to $\mathrm{CO}$ ), and it is unclear whether such processes differ in any meaningful way from similar effects seen with reperfusion injury [17]. It is clear that organs with the highest oxygen demand are the most susceptible to injury, and brain and cardiac effects dominate acute clinical features and also risk assessment for late or permanent effects. There is potential for both serious delayed neurotoxicity (including Parkinsonism and memory and concentration impairment) and cardiotoxicity (myocardial injury and reduced life-expectancy).

It is also apparent that many of the early non-specific clinical effects (for example, headache, nausea, and tachycardia) occurring at $\mathrm{COHb}$ concentrations of less than around $40 \%$ are likely to be signs of compensatory homeostatic responses rather than tissue hypoxemia. To maintain oxygen delivery to the brain, a large compensatory increase in cardiac output is required (as at altitude or with anemia). Unfortunately, any rise in cardiac output and respiratory rate also greatly accelerates $\mathrm{CO}$ uptake. At a critical $\mathrm{COHb}$ and time point, which likely varies considerably between individuals, the heart becomes unable to deliver a cardiac output great enough to compensate for the reduced oxygen-carrying capacity. At this stage, cardiac hypoxia will reduce cardiac output and exacerbate severe tissue hypoxia and death will rapidly occur unless there is intervention (Figure 1). The signs and investigations indicating that this critical tipping point has been passed (that is, more than transient loss of consciousness and elevated neuronal or cardiac injury biomarkers) have all been established as strong markers of short- and long-term prognosis [18-20]. The ability of the individual to compensate for the decreased oxygen-carrying capacity determines the level at which these more severe manifestations become apparent, and those with underlying anemia or respiratory, cardiac, or vascular disease may develop severe toxicity at lower concentrations.

\section{Long-term sequelae and prognostication}

The long-term consequences in survivors can range from severe brain damage (which is fortunately uncommon) to a much more common syndrome of less severe but persistent problems. Neurological sequelae are often divided into persistent neurologic sequelae (PNS) and delayed neurologic sequelae (DNS) $[1,21]$. The incidence of neurological sequelae depends very much on the definition applied, the extent and timing of the assessment, and the population studied.

The concept of persistent neurological injury after a hypoxic brain injury is straightforward. DNS, in contrast, lacks a consistent definition, diagnostic criteria, or an established mechanism. However, the apparent development of the first neuropsychological symptoms or signs occurring days to weeks after $\mathrm{CO}$ poisoning clearly occurs. DNS varies very widely in studies from a few percent to two thirds of patients [22-25]. However, the ratio of DNS to PNS appears much lower when studies are prospective and careful monitoring is done from the beginning (that is, DNS may sometimes reflect delayed diagnosis rather than delayed appearance of symptoms).

Neurological sequelae are most commonly subjective and affect mood, short-term memory, attention, and 


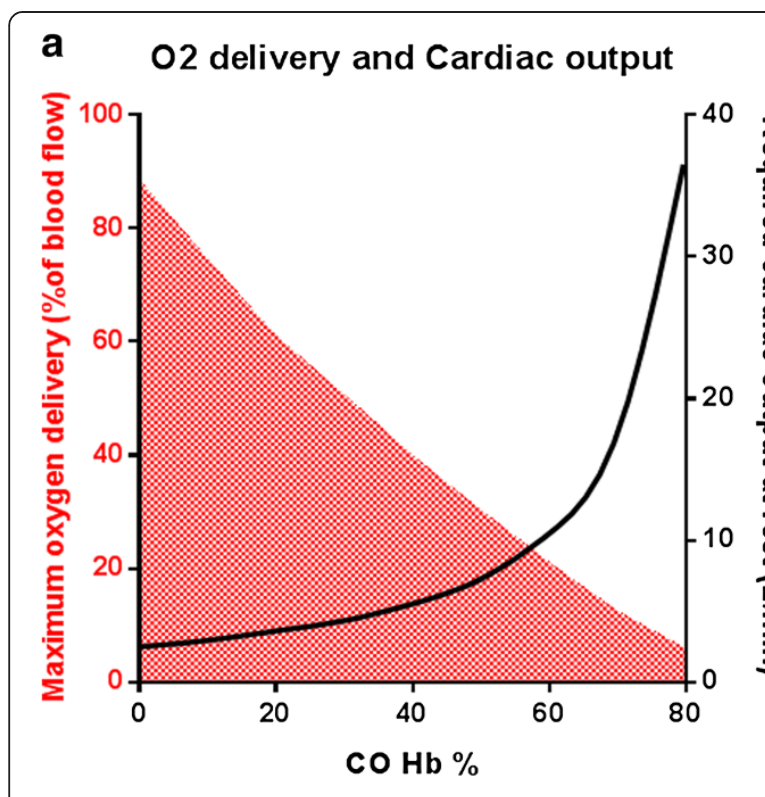

b

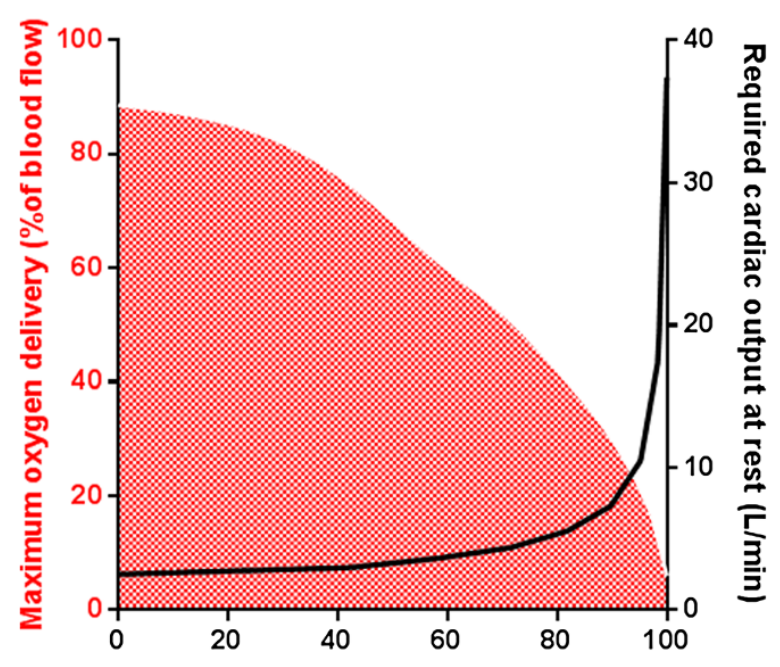

Time ( $\%$ - inhaling $\mathrm{CO}$ before inevitable death)

Figure 1 Carboxyhemoglobin $(\mathrm{COHb})$ versus oxygen delivery capacity of the blood and increased cardiac output required to deliver the same amount of oxygen. (a) This is shown with a linear progression in $\mathrm{COHb}$. (b) In the more likely scenario, there is continuous exposure to $\mathrm{COHb}$ and the rate of uptake of $\mathrm{COHb}$ is roughly proportional to cardiac output, resulting in a very rapid deterioration to life-threatening poisoning, after a relatively long mild poisoning stage. $\mathrm{CO}$, carbon monoxide; $\mathrm{O}_{2}$, oxygen.

concentration. The most common problems encountered are depressed mood (even in those accidentally exposed) and difficulty with higher intellectual functions (especially short-term memory and concentration). More severe problems include areas typically affected by 'watershed' infarcts (for example, basal ganglia and memory). In some cases, these are not noted initially but present later after initial recovery (typically within a week of the exposure). Neuro-psychological testing may be useful to provide objective measures of subtle deficits not found with routine bedside mental state examination and also to monitor the progress of these sequelae. Long-term follow-up is necessary in those at risk, as more subtle defects can develop or become apparent over a few weeks to months. However, the long-term prognosis is favorable in the majority of cases, and symptoms gradually resolve over the first few months [26], and the overwhelming majority of patients with $\mathrm{CO}$ poisoning return to full-time work [27].

Identification of patients who are at risk of neurological sequelae serves an important role in terms of counseling and indicating the extent of follow-up warranted. The best identified risk factors for long-term neurological effects are early and obvious neurological damage or a sustained loss of consciousness during the $\mathrm{CO}$ exposure. Most studies have found that significant neuropsychological sequelae are confined largely to those who have loss of consciousness at some stage [27-29]. However, if less stringent criteria are used for neurological sequelae (that is, slightly low test scores), other risk factors are thrown up by univariate analysis (for example, prolonged or repeated exposures and older age). These risk factors may also represent confounding, or reverse causality (for example, older age is linked to a higher risk of poor memory and executive function irrespective of $\mathrm{CO}$ poisoning; and impaired cognition prior to exposure is a risk for prolonged or repeated $\mathrm{CO}$ exposures) [28]. The recent promulgation of such criteria as age of more than 36 years (irrespective of the absence of other more established risk factors) to guide risk assessment $[26,28]$ or to alter treatment has little to recommend it; it greatly inflates the numbers perceived to be at risk and goes against the much stronger evidence of a relatively benign long-term outcome for $\mathrm{CO}$ poisonings without the established risk factors.

However, other objective ways to identify patients at risk of sequelae are also required, as the history of loss of consciousness may be complicated in some settings. Neuron-specific enolase (NSE) is a glycolytic enzyme that is localized primarily to the neuronal cytoplasm in the central nervous system. S100B is a calcium-binding protein localized to astroglial cells [30]. They are both released after hypoxic damage as a result of neuronal and astroglial cell death [31]. These markers show considerable promise as intermediate outcome measures for brain injury in both animals [32] and humans [19].

Studies to date in acute $\mathrm{CO}$ poisoning confirm this promise. In one recent Taiwan study, 10 out of 71 patients developed DNS. These patients not only had longer loss of consciousness but also had 15-fold higher S100B levels. Further statistical analysis demonstrated that this was an independent predictor of the 
development of DNS after acute CO poisoning: serum S100B of more than $0.165 \mu \mathrm{g} / \mathrm{L}$ predicted DNS with a sensitivity of $90 \%$ and a specificity of $87 \%$ (odds ratio $121,95 \%$ confidence interval 4 to 3,467) [19]. The timing of S100B measurement is critical in interpretation, and high initial levels were associated with coma and cardiac injury but these dropped fourfold within 6 hours [33]. This and other studies have reported generally lower levels and only a minor association with $\mathrm{CO}$ poisoning with loss of consciousness but without such sequelae [34]. Further larger and long-term studies including more people with severe poisoning are required to clarify the optimal timing and threshold and the extent to which a normal S100B can be regarded as reassuring with respect to long-term prognosis. In general, results for NSE have shown a less obvious relationship to severity than S100B [33,34], although one study found that it was better linked to level of consciousness and also had a longer apparent half-life [30]. No studies to date have examined the relationship between NSE elevation and long-term sequelae.

\section{Toxicity assessment}

The severity of poisoning is a function of the duration of exposure, the ambient concentration of $\mathrm{CO}$, and the underlying health status of the exposed individual. $\mathrm{COHb}$ concentrations are a rough guide to the severity of exposure. Venous $\mathrm{COHb}$ levels predict arterial levels with a high degree of accuracy, and the difference between the two is unlikely to exceed $1 \%$ to $2 \%$ $\mathrm{COHb}$ [35].

Though useful for diagnosis when detected, the first measured $\mathrm{COHb}$ is not a reliable way to measure severity or predict long-term outcome $[28,36]$. The $\mathrm{COHb}$ measurement is often delayed. Furthermore, backwards extrapolation based on estimated half-life performs poorly. This is likely because of undefined factors in the highly variable elimination half-life, which depends on not only inhaled oxygen but also cardio-respiratory function. For example, isocapnoic-induced hyperventilation can increase $\mathrm{CO}$ elimination to the same extent as $\mathrm{HBO}$ [37].

The potential use of non-invasive pulse $\mathrm{CO}$ oximeters to obtain rapid, continuous, and field measurements for triage and monitoring has much appeal. There is a Food and Drug Administration-approved device (Masimo Rad-57 signal extraction pulse CO oximeter), but the pre-registration studies tested the accuracy of this machine using only healthy volunteers and $\mathrm{COHb}$ levels up to $15 \%$ [38]. Later clinical studies suggest that the machine should not be used, unless blood gases are not available. For example, in 120 patients presenting to an emergency department with simultaneous blood gases and pulse $\mathrm{CO}$ oximetry, the limits of agreement of the differences in measurement were $-11.6 \%$ and $14.4 \%$ COHB. This greatly exceeds the $\pm 5 \%$ COHB defined as a clinically acceptable difference. Furthermore, a third of patients had a difference between their results of greater than $\pm 5 \% \mathrm{COHb}$, and the RAD-57 device detected $\mathrm{COHb}$ of only more than $15 \%$ with a sensitivity of $48 \%$. Such results mean that the device clearly cannot be used to replace standard laboratory measurements or even triage those requiring formal measurements [39]. The role of this device may be restricted to situations in which detection of chronic low level exposures leading to $\mathrm{COHb}$ of less than $15 \%$ might serve an occupational health role.

The standard method to assess severity of exposure is to focus on neurological and cardiac symptoms indicating tissue hypoxia, such as loss of consciousness and chest pain. Objective evidence of ischemic damage may manifest with neurological signs, but detection of cardiac ischemia requires investigations looking for electrocardiography (ECG) changes and cardiac enzyme elevation (that is, troponin and CK-MB). Myocardial injury is very common, particularly in those with loss of consciousness or underlying vascular disease or both [40]. A prospective study of transthoracic echocardiography on 40 patients with $\mathrm{CO}$ exposure found that $50 \%$ had left ventricular systolic dysfunction. On repeat testing in 3 days, the majority ( $80 \%$ ) had completely recovered [41]. These changes are not usually simply uncovering pre-existing coronary artery disease. In one small study, all coronary angiograms in 20 patients with elevated cardiac markers following $\mathrm{CO}$ poisoning showed normal coronary arteries [42].

Directly attributable long-term cardiac consequences (for example, ischemic cardiomyopathy) are unusual; however, a much higher mortality rate has been reported in those with a troponin rise after $\mathrm{CO}$ poisoning [20]. It is currently unclear whether this represents long-term cardiac sequelae or whether these markers occurred in those with underlying cardiovascular risk factors.

\section{Management}

The widely endorsed aspects of management include removing the patient from the source of exposure and administering oxygen. Management should include the following:

- $100 \%$ oxygen by non-re-breather mask (or ventilator) as soon as possible. Four to six hours of $100 \%$ normobaric oxygen will remove over $90 \%$ of the CO.

- Assessment of severity and potential for coexistent poisonings as above, including 12 lead ECG and electrolytes, full blood count, and COHb.

- Supportive care: ensure that the airway is maintained for those with impaired consciousness, with intubation if necessary; ensure that the patient 
is quiet and resting as unnecessary muscle activity increases oxygen demand.

- Obtain serial ECG and cardiac enzymes in patients with a history of sustained loss of consciousness, cardiovascular disease, chest pain, or ECG changes.

The main therapeutic goal is to prevent acute and chronic neuropsychiatric consequences. Oxygen is the most important treatment and is always indicated for at least 6 hours. Oxygen toxicity is unlikely with less than 24 hours of treatment. Currently, the evidence for any treatment beyond $100 \%$ oxygen is very weak [43].

\section{Hyperbaric oxygen}

HBO therapy is defined as the breathing of $100 \%$ oxygen by patients within hyperbaric chambers compressed to greater than $1.4 \mathrm{~atm}$ of absolute pressure. The half-life of $\mathrm{CO}$ in room air is around 4 to 5 hours. These half-life values decrease to approximately 40 to 80 minutes with administration of ' $100 \%$ oxygen' and to 23 minutes when hyperbaric ( $2 \mathrm{~atm}$ ) oxygen is used (Figure 2a). However, given that the half-life is only around 90 minutes with high-flow oxygen and that it typically takes at least 2 hours to arrange $\mathrm{HBO}$ treatment $[4,44]$, the biological rationale that $\mathrm{HBO}$ is a more effective means of removing $\mathrm{CO}$ in practice is limited (Figure $2 \mathrm{~b}$ ).

It has been suggested that HBO may decrease the risk of neuropsychiatric sequelae due to other mechanisms not dependent on enhancing $\mathrm{CO}$ elimination. However, HBO might also feasibly increase oxidative stress during recovery and is substantially more expensive than normobaric oxygen. Furthermore HBO therapy can occasionally be complicated by barotrauma [21], seizures [45], pulmonary edema, and claustrophobia. It is contraindicated if there has been chest trauma or if the patient requires close monitoring or is non-cooperative.

The term HBO therapy covers a broad range of treatments; one survey of North American hyperbaric facilities found 18 different protocols. Among these protocols, the shortest period of compression lasts 46 minutes whereas the longest lasted 3 hours [46]. Some centers use multiple compressions over several days. All of these protocols are lacking evidence to support their choice over any other protocol or indeed that they improve outcomes in human poisoning.

The stated goal of hyperbaric treatment is the prevention of long-term and permanent neurocognitive dysfunction; no study has yet demonstrated a reduction in mortality [47,48]. A 2011 systematic review (Cochrane collaboration) identified six randomized clinical trials that have compared $\mathrm{HBO}$ versus normobaric $100 \%$ oxygen [43]. Four of these studies reported negative and two positive outcomes at 4 to 6 weeks. The negative studies had mostly subjective outcome measures of

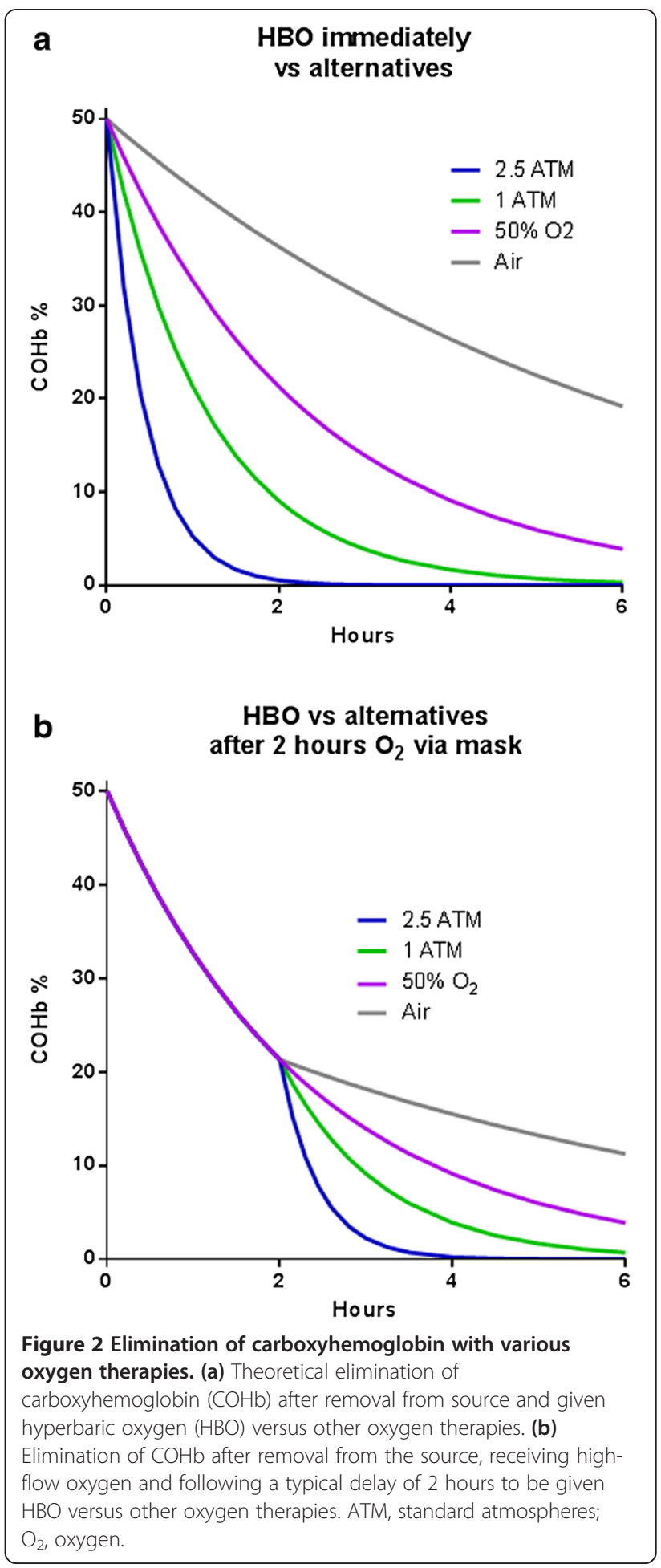

neurological recovery and may feasibly have overlooked clinically important benefits. In contrast, it was evident that there was a high risk of bias from the approach to analysis applied in the positive studies. The largest positive trial was prematurely stopped 'for benefit' but despite this would have been a 'negative' study but for the 
numerous assumptions and protocol variations (including a change in the primary outcome) that all favored showing benefit from HBO [22]. Furthermore, a recent study comparing one versus two HBO sessions in comatose patients found more neurological sequelae in the group with repeated HBO [27] (Figure 3).

The role of $\mathrm{HBO}$ in the acute management of patients with very severe $\mathrm{CO}$ poisoning, such as coma, seizures, severe metabolic acidosis, or cardiac dysfunction, is particularly unclear as controlled clinical trials have frequently excluded such patients. If rapidly available, $\mathrm{HBO}$ may be the most effective mechanism for treating hypoxia in such patients; however, it may also be difficult to use unless a multi-person chamber is available so that medical/nursing care can continue uninterrupted.

Even among those advocating $\mathrm{HBO}$, controversy exists about the indications for use of $\mathrm{HBO}$ in $\mathrm{CO}$ poisoning. Recommendations for the use of $\mathrm{HBO}$ in $\mathrm{CO}$ poisoning vary greatly between guidelines. The American College of Emergency Physicians clinical guidelines committee state: 'HBO is a therapeutic option for CO-poisoned patients; however, its use cannot be mandated. No clinical variables, including $\mathrm{COHb}$ levels, identify a subgroup of $\mathrm{CO}$-poisoned patients for whom $\mathrm{HBO}$ is most likely to provide benefit or cause harm' [49]. Similarly, the National Institute for Health Care Excellence: Clinical Knowledge Summaries advise treatment with 100\% oxygen, preferably via a face mask with reservoir. They do not currently recommend treatment with $\mathrm{HBO}$, as 'there is insufficient evidence' that HBO 'improves long-term outcomes of people with severe carbon monoxide poisoning, compared with standard oxygen treatment' [50].

In contrast, the Undersea and Hyperbaric Medical Society has much broader recommendations and suggests $\mathrm{HBO}$ therapy for patients with serious $\mathrm{CO}$ poisoning, as manifested by transient or prolonged unconsciousness, abnormal neurologic signs, cardiovascular dysfunction, or severe acidosis, or for patients who are 36 years of age or older and were exposed for 24 hours or more (including intermittent exposures) or who have a $\mathrm{COHb}$ level of $25 \%$ or more [26]. Four authors who are prominent in this society have published similar recommendations [47].

In conclusion, $\mathrm{HBO}$ has a plausible but not compelling rationale, is of unknown effectiveness, and has some risks including that it might feasibly worsen neuropsychological sequelae. The risk/benefit will remain unclear until a large multi-center double-blind randomized controlled trial examining long-term clinical outcomes is performed; however, no such trials are currently registered as ongoing.

\section{Pharmacological treatments}

A diverse group of pharmacological treatments has been investigated as treatment options in $\mathrm{CO}$ poisoning, with the aim of decreasing the rate of neurological sequelae. We have highlighted those agents that have already been proven safe for use in humans for other indications.

Erythropoietin (EPO) is a cytokine that originally was identified for its role in erythropoiesis and more recently was shown to be produced in the central nervous system. EPO offers neuronal protection when administered systemically to animals with global and focal cerebral ischemia. EPO administration led to substantial dosedependent reduction in S100B following CO poisoning in an animal model [51]. A randomized prospective study of 103 patients with CO poisoning compared subcutaneous EPO for a week with placebo. S-100 $\beta$ levels decreased more rapidly in patients in the EPO group, and stroke scores were also better. At 30 days, fewer

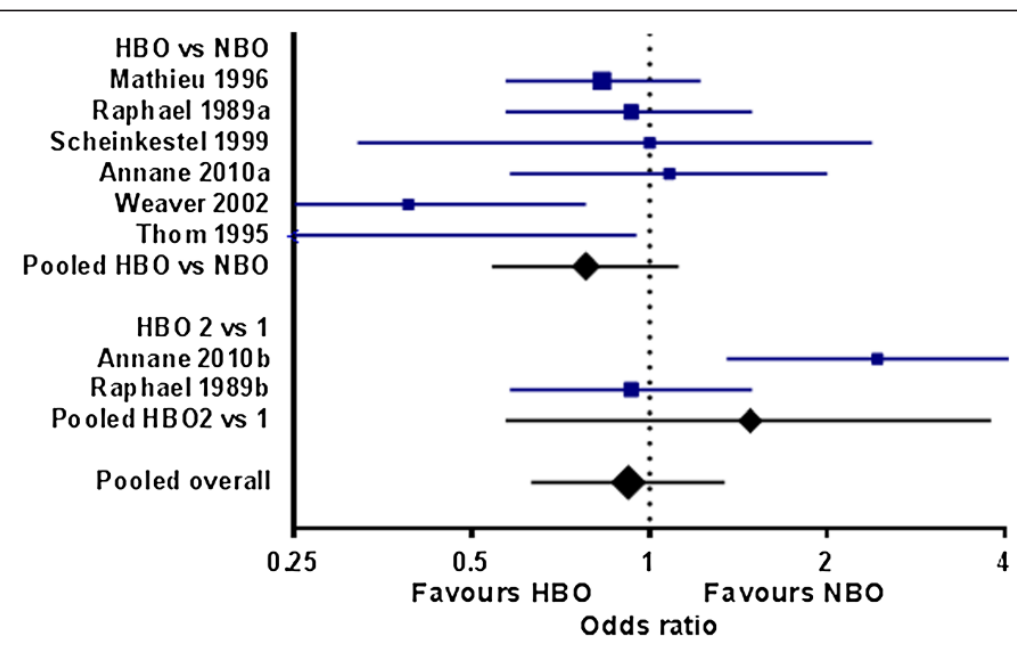

Figure 3 Forest plot of treatment effects seen in randomized controlled trials of hyperbaric oxygen therapy. HBO, hyperbaric oxygen; $\mathrm{NBO}$, normobaric oxygen. 
patients in the EPO group had delayed neurologic sequelae $(12 \%$ versus $30 \%, P=0.021)$ [52]. However, enthusiasm should be tempered by the experience with EPO in stroke, in which favorable small studies were followed by a large negative study that showed a higher death rate in the EPO arm [53].

Another novel treatment that has been repeatedly studied in animals for acute $\mathrm{CO}$ poisoning is hydrogenrich saline. Hydrogen-rich saline is an anti-oxidant that at this stage is currently used in Japan for human metabolic disorders. It is non-toxic, convenient, and safe to use. It has been shown in rat studies to decrease neuronal necrosis and apoptosis, and improve neurobehavioral function, following $\mathrm{CO}$ poisoning. Its suggested mechanisms of action include reducing reactive oxygen species levels and upregulating endogenous antioxidative enzymes [54-56].

A diverse group of other substances has been tested in animal studies and has shown possible benefit, including granulocyte colony-stimulating factor, nimodipine, fructose diphosphate, hyperoxygenated solution and edaravone [57-60]. An even more diverse group of substances has been shown to be effective in hypoxic/reperfusion injury. The use of any of these agents cannot be recommended outside of clinical trials; however, there may be more rational treatments to test further in clinical trials to prevent neurological damage from reactive oxygen species than $\mathrm{HBO}$.

\section{Conclusions}

The mainstay of management of $\mathrm{CO}$ poisoning involves early $100 \%$ oxygen therapy. It is important to identify patients at high risk of neuropsychological sequelae, and the best established predictor is prolonged loss of consciousness. However, new biomarkers such as S100B show considerable potential to improve this prediction. Better validated objective predictive tools would greatly assist in the assessment of new and old treatments. The benefits, risks, and indications for HBO remain unclear despite six randomized controlled trials. Pharmacological treatments that reduce reperfusion injury and apoptosis, such as EPO, show considerable potential. These have a stronger biological rationale and would be more widely available, rapidly administered, and less expensive. Large multi-center trials with objective and functional longterm outcomes are needed for both old and new treatments before they can be recommended.

\section{Abbreviations}

CO: Carbon monoxide; $\mathrm{COHb}$ : Carboxyhemoglobin; DNS: Delayed neurologic sequelae; ECG: Electrocardiography; EPO: Erythropoietin; HBO: Hyperbaric oxygen; NSE: Neuron-specific enolase; PNS: Persistent neurologic sequelae.

\section{Competing interests}

The authors declare that they have no competing interests.

\section{Authors' contributions}

ALC and NAB performed the literature search, drafted the manuscript, and performed the revisions. NAB designed the figures. Both authors read and approved the final manuscript.

\section{Author details}

${ }^{1}$ Clinical and Experimental Toxicology Unit, Department of Emergency Medicine, Prince of Wales Hospital, Barker Street, Randwick, NSW 2031 Australia. ${ }^{2}$ Pharmacology, Sydney Medical School, University of Sydney, Sydney, NSW 2006, Australia. ${ }^{3}$ NSW Poisons Information Centre, The Children's Hospital, Westmead, Sydney, NSW 2145, Australia.

\section{Published: 28 Apr 2014}

\section{References}

1. Weaver L: Carbon monoxide poisoning. Crit Care Clin 1999, 15:297-317.

2. Hampson N: Emergency department visits for carbon monoxide poisoning. J Emerg Med 1998, 16:695-698.

3. Centers for Disease Control and Prevention (CDC): Carbon monoxide exposures - United States, 2000-2009. MMWR 2011, 60:1014-1017.

4. Hampson NB, Dunn SL, UHMCS/CDC CO Poisoning Surveillance Group: Symptoms of carbon monoxide poisoning do not correlate with the initial carboxyhemoglobin level. Undersea Hyperb Med 2012, 39:657-665.

5. Brennan C, Routley V, Ozanne-Smith J: Motor vehicle exhaust gas suicide in Victoria, Australia 1998-2002. Crisis 2006, 27:119-124.

6. Liu KY, Beautrais A, Caine E, Chan K, Chao A, Conwell Y, Law C, Lee D, Li P, Yip P: Charcoal burning suicides in Hong Kong and urban Taiwan: an illustration of the impact of a novel suicide method on overall regional rates. J Epidemiol Community Health 2007, 61:248-253.

7. Chen YY, Chen F, Gunnell D, Yip PS: The impact of media reporting on the emergence of charcoal burning suicide in Taiwan. PLoS One 2013, 8:e55000.

8. Mott JA, Wolfe MI, Alverson CJ, Macdonald SC, Bailey CR, Ball LB, Moorman JE, Somers JH, Mannino DM, Redd SC: National vehicle emissions policies and practices and declining US carbon monoxide-related mortality. JAMA 2002, 288:988-995.

9. Kreitman N: The coal gas story. United Kingdom suicide rates, 1960-71. Br J Prev Soc Med 1976, 30:86-93.

10. Surtees PG, Duffy JC: Suicide in England and Wales 1946-1985: an age-period-cohort analysis. Acta Psychiatr Scand 1989, 79:216-223.

11. Hepp U, Ring M, Frei A, Rössler W, Schnyder U, Ajdacic-Gross V: Suicide trends diverge by method: Swiss suicide rates 1969-2005. Eur Psychiatry 2010, 25:129-135.

12. Piantadosi C: Diagnosis and treatment of carbon monoxide poisoning Resp Care Clin North Am 1999, 5:183-202.

13. Brown SD, Piantadosi CA: Recovery of energy metabolism in rat brain after carbon monoxide hypoxia. J Clin Invest 1992, 89:666-672.

14. Zhang J, Piantadosi CA: Mitochondrial oxidative stress after carbon monoxide hypoxia in the rat brain. J Clin Invest 1992, 90:1193-1199.

15. Thom SR, Bhopale VM, Han ST, Clark JM, Hardy KR: Intravascular neutrophil activation due to carbon monoxide poisoning. Am J Respir Crit Care Med 2006, 174:1239-1248.

16. Thom SR, Bhopale VM, Fisher D, Zhang J, Gimotty P: Delayed neuropathology after carbon monoxide poisoning is immune-mediated. Proc Natl Acad Sci U S A 2004, 101:13660-13665.

17. Heiss WD: The ischemic penumbra: how does tissue injury evolve? Ann N Y Acad Sci 2012, 1268:26-34.

18. Pepe G, Castelli M, Nazerian P, Vanni S, Del Panta M, Gambassi F, Botti P, Missanelli A, Grifoni S: Delayed neuropsychological sequelae after carbon monoxide poisoning: predictive risk factors in the Emergency Department, A retrospective study. Scand J Trauma Resusc Emerg Med 2011, 19:16.

19. Park E, Ahn J, Min YG, Jung YS, Kim K, Lee J, Choi SC: The usefulness of the serum s100b protein for predicting delayed neurological sequelae in acute carbon monoxide poisoning. Clin Toxicol 2012, 50:183-188.

20. Henry CR, Satran D, Lindgren B, Adkinson C, Nicholson Cl, Henry TD: Myocardial injury and long-term mortality following moderate to severe carbon monoxide poisoning. JAMA 2006, 295:398-402.

21. Weaver LK: Carbon monoxide poisoning. N Engl J Med 2009, 360:1217-1225. 
22. Weaver LK, Hopkins RO, Chan KJ, Churchill S, Elliott CG, Clemmer TP, Orme JF Jr, Thomas FO, Morris AH: Hyperbaric oxygen for acute carbon monoxide poisoning. N Engl J Med 2002, 347:1057-1067.

23. Parkinson RB, Hopkins RO, Cleavinger HB, Weaver LK, Victoroff J, Foley JF, Bigler ED: White matter hyperintensities and neuropsychological outcome following carbon monoxide poisoning. Neurology 2002, 58:1525-1532.

24. Deschamps D, Géraud C, Julien H, Baud FJ, Dally S: Memory one month after acute carbon monoxide intoxication: a prospective study. Occup Environ Med 2003, 60:212-216.

25. Scheinkestel CD, Bailey M, Myles PS, Jones K, Cooper DJ, Millar IL, Tuxen DV: Hyperbaric or normobaric oxygen for acute carbon monoxide poisoning: a randomised controlled clinical trial. Med J Australia 1999, 170:203-210.

26. Lippi G, Rastelli G, Meschi T, Borghi L, Cervellin G: Pathophysiology, clinics, diagnosis and treatment of heart involvement in carbon monoxide poisoning. Clin Biochem 2012, 45:1278-1285

27. Annane D, Chadda K, Gajdos P, Jars-Guincestre MC, Chevret S, Raphael JC: Hyperbaric oxygen therapy for acute domestic carbon monoxide poisoning: two randomized controlled trials. Intensive Care Med 2011 37:486-492.

28. Weaver LK, Valentine KJ, Hopkins RO: Carbon monoxide poisoning: risk factors for cognitive sequelae and the role of hyperbaric oxygen. Am J Respir Crit Care Med 2007, 176:491-497.

29. Raphael JC, Elkharrat D, Jars-Guincestre MC, Chastang C, Chasles V, Vercken JB, Gajdos P: Trial of normobaric and hyperbaric oxygen for acute carbon monoxide intoxication. Lancet 1989, 2:414-419.

30. Akelma AZ, Celik A, Ozdemir O, Kavak Akelma F, Abaci A, Razi CH, Kislal FM, Akin O: Neuron-specific enolase and S100B protein in children with carbon monoxide poisoning: children are not just small adults. Am J Emerg Med 2013, 31:524-528.

31. Berger RP, Pierce MC, Wisniewski SR, Adelson PD, Clark RS, Ruppel RA, Kochanek PM: Neuron-specific enolase and S100B in cerebrospinal fluid after severe traumatic brain injury in infants and children. Pediatrics 2002, 109:E31.

32. Brvar M, Finderle Z, Suput D, Bunc M: S100B protein in conscious carbon monoxide-poisoned rats treated with normobaric or hyperbaric oxygen. Crit Care Med 2006, 34:2228-2230

33. Cakir Z, Aslan S, Umudum Z, Acemoglu H, Akoz A, Turkyilmaz S, Oztürk N: S-100beta and neuron-specific enolase levels in carbon monoxiderelated brain injury. Am J Emerg Med 2010, 28:61-67.

34. Yardan T, Cevik Y, Donderici O, Kavalci C, Yilmaz FM, Yilmaz G, Vural K, Yuzbasioglu Y, Gunaydin YK, Sezer AA: Elevated serum S100B protein and neuron-specific enolase levels in carbon monoxide poisoning. Am J Emerg Med 2009, 27:838-842.

35. Touger M, Gallagher EJ, Tyrell J: Relationship between venous and arterial carboxyhemoglobin levels in patients with suspected carbon monoxide poisoning. Ann Emerg Med 1995, 25:481-483.

36. Hampson NB, Hauff NM: Carboxyhemoglobin levels in carbon monoxide poisoning: do they correlate with the clinical picture? Am J Emerg Med 2008, 26:665-669.

37. Fisher JA, Rucker J, Sommer LZ, Vesely A, Lavine E, Greenwald Y, Volgyesi G, Fedorko L, Iscoe S: Isocapnic hyperpnea accelerates carbon monoxide elimination. Am J Respir Crit Care Med 1999, 159:1289-1292.

38. Barker SJ, Curry J, Redford D, Morgan S: Measurement of carboxyhemoglobin and methemoglobin by pulse oximetry. Anesthesiology 2006, 105:892-897.

39. Touger M, Birnbaum A, Wang J, Chou K, Pearson D, Bijur P: Performance of the RAD-57 pulse CO-Oximeter compared with standard laboratory carboxyhemoglobin measurements. Ann Emerg Med 2010, 56:382-387.

40. Satran D, Henry CR, Adkinson C, Nicholson Cl, Bracha Y, Henry TD: Cardiovascular manifestations of moderate to severe carbon monoxide poisoning. J Am Coll Cardiol 2005, 45:1513-1516.

41. Ahn KT, Park JH, Kim MS, Park YS, Kim YJ, Lee IS, Kim JH, Lee JH, Choi SW, Jeong JO, Seong IW: Prevalence and clinical outcomes of left ventricular systolic dysfunction after carbon monoxide exposure. Int J Cardiol 2011, 153:108-110.

42. Kalay N, Ozdogru I, Cetinkaya Y, Eryol NK, Dogan A, Gul I, Inanc T, Ikizceli I, Oguzhan A, Abaci A: Cardiovascular effects of carbon monoxide poisoning. Am J Cardiol 2007, 99:322-324.
43. Buckley NA, Juurlink DN, Isbister G, Bennett MH, Lavonas EJ: Hyperbaric oxygen for carbon monoxide poisoning. Cochrane Database Syst Rev 2011, 4:Cd002041.

44. Hampson NB: Noninvasive pulse CO-oximetry expedites evaluation and management of patients with carbon monoxide poisoning. Am J Emerg Med 2012, 30:2021-2024

45. Sanders RW, Katz KD, Suyama J, Akhtar J, OToole KS, Corll D, Ladenburger $\mathrm{RN}$ : Seizure during hyperbaric oxygen therapy for carbon monoxide toxicity: a case series and five-year experience. J Emerg Med 2012, 42:e69-e72.

46. Hampson NB, Dunford RG, Norkool DM: Treatment of carbon monoxide poisonings in multiplace hyperbaric chambers. J Hyperbaric Med 1992, 7:165-171

47. Hampson NB, Piantadosi CA, Thom SR, Weaver LK: Practice recommendations in the diagnosis, management, and prevention of carbon monoxide poisoning. Am J Respir Crit Care Med 2012, 186:1095-1101.

48. Hampson NB, Hauff NM: Risk factors for short-term mortality from carbon monoxide poisoning treated with hyperbaric oxygen. Crit Care Med 2008, 36:2523-2527.

49. Wolf SJ, Lavonas EJ, Sloan EP, Jagoda AS, American College of Emergency Physicians: Critical issues in the management of adult patients presenting to the emergency department with acute carbon monoxide poisoning. Ann Emerg Med 2008, 51:138-152.

50. National Institute for Health and Care Excellence (NICE): Clinical Knowledge Summaries: Carbon Monoxide Poisoning. [http://cks.nice.org.uk/carbonmonoxide-poisoning\#azTab].

51. Shahsavand S, Mohammadpour AH, Rezaee R, Behravan E, Sakhtianchi R, Moallem SA: Effect of erythropoietin on serum brain-derived biomarkers after carbon monoxide poisoning in rats. Iran J Basic Med Sci 2012, 15:752-758.

52. Pang $L$, Bian M, Zang XX, Wu Y, Xu DH, Dong N, Wang ZH, Yan BL, Wang DW, Zhao HJ, Zhang N: Neuroprotective effects of erythropoietin in patients with carbon monoxide poisoning. J Biochem Molecular Toxicology 2013, 27:266-270.

53. Ehrenreich $H$, Weissenborn $K$, Prange $H$, Schneider D, Weimar C, Wartenberg K, Schellinger PD, Bohn M, Becker H, Wegrzyn M, Jähnig P, Herrmann M, Knauth M, Bähr M, Heide W, Wagner A, Schwab S, Reichmann H, Schwendemann G, Dengler R, Kastrup A, Bartels C, EPO Stroke Trial Group: Recombinant human erythropoietin in the treatment of acute ischemic stroke. Stroke 2009, 40:e647-e656.

54. Wang W, Tian L, Li Y, Wang X, Xia F, Li L, Li J, Zhang Z: Effects of hydrogen-rich saline on rats with acute carbon monoxide poisoning. J Emerg Med 2013, 44:107-115.

55. Shen MH, Cai JM, Sun Q, Zhang DW, Huo ZL, He J, Sun XJ: Neuroprotective effect of hydrogen-rich saline in acute carbon monoxide poisoning. CNS Neurosci Ther 2013, 19:361-363.

56. Sun Q, Cai J, Zhou J, Tao H, Zhang JH, Zhang W, Sun XJ: Hydrogen-rich saline reduces delayed neurologic sequelae in experimental carbon monoxide toxicity. Crit Care Med 2011, 39:765-769.

57. Ghorbani M, Moallem S, Abnous K, Tabatabaee Yazdi SA, Movassaghi AR, Azizzadeh M, Mohamadpour AH: The effect of granulocyte colonystimulating factor administration on carbon monoxide neurotoxicity in rats. Drug Chem Toxicol 2013, 36:102-108.

58. Yang J, Zhao X, Zhou Q, Jiang Q: Effects of nimodipine and fructose-1 6-diphosphate on cerebral damage in carbon monoxide poisoning mice. Chin Med J (Engl) 2003, 116:1911-1915.

59. Qingsong W, Yeming G, Xuechun L, Hongjuan L, Jing W: The free radical scavenger, edaravone, ameliorates delayed neuropsychological sequelae after acute carbon monoxide poisoning in rabbits. Undersea Hyperb Med 2013, 40:223-229.

60. Sun X, Xu H, Meng X, Qi J, Cui Y, Li Y, Zhang H, Xu L: Potential use of hyperoxygenated solution as a treatment strategy for carbon monoxide poisoning. PLOS One 2013, 8:e81779.

$10.1186 / \mathrm{cc} 13846$

Cite this article as: Chiew and Buckley: Carbon monoxide poisoning in the 21 st century. Critical Care 2014, 18:221 